\section{The coagulopathy in sepsis: significance and implications for treatment}

\author{
Paola Saracco, ${ }^{1}$ Pasquale Vitale, ${ }^{2}$ \\ Carlo Scolfaro, 3 Berardino Pollio, 4 \\ Mauro Pagliarino, 5 Fabio Timeus 6 \\ 1Hematology Unit, Department of \\ Pediatrics, University of Turin; \\ 2Pediatric Intensive Care Unit, Emergency \\ Department, Regina Margherita S. Anna \\ Hospital; 3Infective Disease Unit, \\ Department of Pediatrics, University \\ of Turin; 4 Immunohematology and \\ Transfusion Medicine Unit, Department \\ of Laboratory diagnostic Services, \\ Regina Margherita S. Anna Hospital; \\ 5 Immunohematology and Transfusion \\ Medicine Unit, Department of Laboratory \\ diagnostic Services, Regina Margherita \\ S.Anna Hospital; ${ }^{6}$ Oncohematology and \\ Stem Cell Transplant Unit, Department \\ of Oncology, Regina Margherita S. Anna \\ Hospital, Turin, Italy
}

\begin{abstract}
Sepsis related coagulopathy ranges from mild laboratory alterations up to severe disseminated intravascular coagulation (DIC). There is evidence that DIC is involved in the pathogenesis of microvascular dysfunction contributing to organ failure. Additionally, the systemic activation of coagulation, by consuming platelets and coagulation factors, may cause bleeding. Thrombin generation via the tissue factor/factor VIIa route, contemporary depression of antithrombin and protein $\mathrm{C}$ anticoagulant systems, as well as impaired fibrin degradation, due to high circulating levels of PAI-1, contribute to enhanced intravascular fibrin deposition. This deranged coagulopathy is an independent predictor of clinical outcome in patients with severe sepsis. Innovative supportive strategies aiming at the inhibition of coagulation activation should comprise inhibition of tissue factor-mediated activation or restoration of physiological anticoagulant pathways, as the administration of recombinant human activated protein $\mathrm{C}$ or concentrate. In spite of some promising initial studies, additional trials are needed to define their clinical effectiveness in adults and children with severe sepsis.
\end{abstract}

Introduction
Sepsis always leads to deranged coagulation, ranging from mild alterations up to severe disseminated intravascular coagulation (DIC). Septic patients with severe DIC can present with manifest thromboembolic disease as purpura fulminans or clinically less apparent microvascular fibrin deposition, predominantly presenting as multiple organ dysfunction. Alternatively, severe bleeding might be the leading symptom, or even coexisting bleeding and thrombosis.1,2 The deranged coagulation, particularly DIC, is an important and independent predictor of clinical outcome in patients with severe sepsis. ${ }^{3-5}$

\section{Mechanism of coagulation activa- tion in DIC}

Initiation of coagulation triggered by proinflammatory cytokines such as IL-6, is tissue factor (TF) dependent. Amplification of thrombin generation is due to tumor necrosis factor (TNF-a) impaired defective physiological anticoagulant mechanisms while propagation of fibrin deposition in the microvasculature is caused by insufficient fibrin degradation, as a result of an inhibited fibrinolytic system. . $^{-9}$

The TF-factor-VIIa complex catalyses the activation of both factors IX and X, enhancing activation of factors $\mathrm{X}$ and prothrombin, respectively. Inducible TF is mainly expressed by monocytes and macrophages, and its expression on monocytes is stimulated by the presence of platelets and granulocytes in a Pselectin-dependent reaction. This cellular interaction also enhances the production of interleukins IL-1b and IL-8, and of tumor necrosis factor a (TNF $\alpha)$.

Dysfunctional anticoagulant pathways

Systemic activation of coagulation upon inflammation is counteracted by several inhibitors such as antithrombin (AT), proteins $\mathrm{C}$ and $\mathrm{S}$, and tissue factor pathway inhibitor (TFPI).

Markedly lowered plasma levels of AT are found in sepsis as a result of both reduced protein synthesis and increased clearance. Under the influence of cytokines, the synthesis of glycosaminoglycans by endothelial cells is reduced, impairing the inhibitory potential of AT. Protein C and its cofactor protein S represents a further defence mechanism. Thrombin binds to the endothelial cell-membrane-associated molecule thrombomodulin, and this complex converts protein $\mathrm{C}$ to its active form, activated protein C (APC). APC inactivates factors Va and VIIIa by proteolytic cleavage, thus slowing the coagulation cascade. Endothelial cells, primarily of large blood vessels, express an endothelial protein $\mathrm{C}$ receptor (EPCR) which augments the activation of protein $\mathrm{C}$ at the cell surface. In patient studies, lowered levels of protein $\mathrm{C}$ and protein $\mathrm{S}$ are associated with increased mortality.
Correspondence: Paola Saracco

Hematology Unit, Department of Pediatrics Piazza Polonia 94, 10126 Turin, Italy.

E.mail paola.saracco@unito.it

Key words: sepsis, disseminated activated coagulation, coagulopathy, treatment.

Received for publication: 6 October 2011. Accepted for publication: 26 October 2011.

This work is licensed under a Creative Commons Attribution NonCommercial 3.0 License (CC BYNC 3.0).

(C) Copyright P. Saracco et al., 2011

Licensee PAGEPress, Italy

Pediatric Reports 2011; 3:e30

doi:10.4081/pr.2011.e30

A third inhibitory mechanism, TFPI, inhibits the TF-factor VIIa complex by forming a quaternary complex with factor Xa. A study in human subjects confirmed the potential of TFPI to block the procoagulant pathway triggered by endotoxin, by binding endotoxin and attenuating Il-6 generation. ${ }^{9,10}$

\section{Dysfunctional fibrinolysis}

There is evidence that fibrinolysis is activated in experimental models of severe infection. This is demonstrated by an initial activation of plasminogen activation followed by a marked impairment, caused by the release of plasminogen activator inhibitor, type 1 (PAI-1), causing a net procoagulant situation. The molecular basis is cytokine-mediated activation of vascular endothelial cells. Endotoxin and TNFa stimulate PAI-1 production in the liver, kidney, lung and adrenals of mice. PAI-1 is the principal inhibitor of fibrinolysis. Recent studies have shown that a functional mutation in the PAI-1 gene (the 4G/5G polymorphism) not only influenced the plasma levels of PAI-1 but was also linked to clinical outcome of meningococcal septicemia. ${ }^{11}$

\section{Platelet activation}

Endotoxin can directly activate platelets, and many pro-inflammatory cytokines are capable of inducing platelet activation. The provision of a suitable phospholipid surface on the activated platelet membrane permits the assembly of complexes of activated coagulation factors, catalyses the generation of thrombin several-fold and renders the coagulation system less susceptible to inhibitors. ${ }^{12}$

\section{Inflammation and coagulation interaction in DIC}

Coagulation proteases and protease inhibitors interact also with specific cell receptors to induce signaling pathways. ${ }^{12}$ Factor Xa, 
thrombin and the TF-factor VIIa complex elicit pro-inflammatory activities. Activated protein $\mathrm{C}$ has anti-inflammatory effects on mononuclear cells and granulocytes, distinct from its anticoagulant activity. This anti-inflammatory activity occurs only when APC gets in contact with its receptor EPCR and activates proteaseactivated receptor PAR-1, which inhibits inflammation and apoptosis. ${ }^{13}$ Several coagulation proteases can induce pro-inflammatory mediators with procoagulant effects which further maintain and amplify DIC.

\section{Implications for therapy}

In case of severe systemic inflammatory response syndrome, the coagulation abnormalities and consequent organ dysfunction might proceed even after initiation of causative agent treatment. Supportive measures to manage the coagulopthy are required which might positively affect morbidity and mortality (Table 1).

Plasma, coagulation factors and platelet substitution therapy

Low levels of platelets and coagulation factors might increase the risk of bleeding. However, plasma or platelet substitution therapy is indicated only in patients with active bleeding or at high risk for bleeding complications. It might be necessary to use large volumes of plasma to correct the coagulation defect. Coagulation factor concentrates, such as prothrombin complex concentrate may be used, but these compounds lack essential factors, such as factor V. Specific deficiencies in coagulation factors, such as fibrinogen, can be corrected by administration of purified coagulation factor concentrates or cryoprecipitate. 5

Repeated measurement of prothrombin time and activated partial thromboplastin time can be useful in monitoring the coagulation defect. In case of a (relative) vitamin $\mathrm{K}$ deficiency, administration of vitamin $\mathrm{K}$ is required. 5

Platelet transfusion can be considered in patients with DIC and severe thrombocytopenia, in particular in patients with bleeding or in patients at risk for bleeding. The threshold for transfusing platelets depends on the clinical condition of the patient. In general, platelet transfusions are administered to patients who bleed and who have a platelet count of $<50 \times$ $109 / \mathrm{L}$. In non-bleeding patients, a much lower threshold for platelet transfusion is used (usually $10-20 \times 10^{9} / \mathrm{L}$ ), which is based on randomized controlled trials in patients with thrombocytopenia following chemotherapy. 5

\section{Use of anticoagulants}

A beneficial effect of heparin on clinically important outcome events in patients with DIC has never been demonstrated in controlled clinical trials. Also, the safety of heparin treatment is controversial in DIC patients who are prone to bleeding. Therapeutic doses of

Table 1. Supportive treatment recommendations for sepsis induced coagulopathy.

\begin{tabular}{|c|c|c|}
\hline Plasma & In patients with active bleeding & Not for prophylaxis \\
\hline $\begin{array}{l}\text { Coagulation factor } \\
\text { concentrates } \\
\text { or cryoprecipitate }\end{array}$ & $\begin{array}{l}\text { In patients with active bleeding } \\
\text { and with specific deficiencies } \\
\text { in coagulation factors }\end{array}$ & $\begin{array}{l}\text { Not recommended for } \\
\text { prophylaxis }\end{array}$ \\
\hline Platelets & $\begin{array}{l}\text { In patients with thrombocytopenia and } \\
\text { active bleeding or at high risk } \\
\text { for bleeding complications }\end{array}$ & $\begin{array}{l}\text { In non-bleeding patients when platelets } \\
<10-20 \times 109 / \mathrm{L} \text {. }\end{array}$ \\
\hline Vitamin $\mathrm{K}$ & In case of relative deficiency & \\
\hline Heparin & $\begin{array}{l}\text { In patients with purpura fulminans or } \\
\text { acral ischemia in absence of bleeding } \\
\text { or of high bleeding risk }\end{array}$ & $\begin{array}{l}\text { Prophylaxis of venous } \\
\text { thromboembolism }\end{array}$ \\
\hline Antithrombin & In case of severe deficiency & Not recommended for prophylaxis \\
\hline $\begin{array}{l}\text { Recombinant } \\
\text { activated Protein C }\end{array}$ & & Drug withdrawn by manufacturer \\
\hline $\begin{array}{l}\text { Protein C } \\
\text { concentrate }\end{array}$ & $\begin{array}{l}\text { In children with severe } \\
\text { shock and high risk mortality } \\
\text { (dysfunction at least } 2 \text { organs) }\end{array}$ & $\begin{array}{l}\text { PICCHE (Pediatric Intensive Care } \\
\text { C protein HEmostasis) } \\
\text { Study ongoing in Italy }\end{array}$ \\
\hline
\end{tabular}

heparin may be indicated in patients with clinically overt thromboembolism or extensive fibrin deposition, like purpura fulminans or acral ischemia. Patients with DIC might benefit from prophylaxis to prevent venous thromboembolism.

Theoretically, the most logical anticoagulant agent to use in DIC is directed against TF activity. Potential agents include recombinant TFPI, inactivated factor VIIa, and recombinant NAPc2, a potent and specific inhibitor of the ternary complex between TF-factor VIIa and factor Xa. In spite of initial promising results, a completed trial did not show an overall survival benefit in patients with sepsis treated with recombinant TFPI. Interestingly, in an $a$ priori defined subgroup of patients with an international normalized ratio of more than 1.2 , TFPI treatment was associated with a more favorable outcome. 14,15

\section{Restoration of anticoagulant pathways}

The use of AT concentrates in patients with DIC and sepsis has been extensively studied. ${ }^{16,17}$ All trials show some beneficial effect in improvement of laboratory parameters, shortening of the duration of DIC, or even improvement in organ function. A large-scale, multicenter, randomized controlled trial (RCT) showed no significant reduction in mortality of septic patients treated with AT concentrate. Surprisingly, subgroup analyses indicated some benefit in patients who did not receive concomitant heparin, but this observation needs prospective validation.

A beneficial effect of recombinant human activated protein $\mathrm{C}$ was demonstrated in several randomized controlled trials. ${ }^{18-23}$ Interestingly, a markedly greater reduction in D-dimer levels and IL-6 was seen at all time points studied in patients receiving activated protein $\mathrm{C}$, indicating its beneficial effect on activation of coagulation and its anti-inflam- matory effect in patients with sepsis. However a recently updated review 24 including a total of five RCTs involving 5,101 participants showed that for 28-day mortality, APC did not reduce the risk of death in adult and pediatric patients with severe sepsis. APC use was associated with an increased risk of bleeding $(\mathrm{P}=0.01)$. Moreover, the recent randomized multinational trial, the Prowess-shock trial, ${ }^{25}$ found no significant reduction in mortality in treated patients compared to placebo and the drug Company has withdrawn drotrecogin alfa from the market by november 2011 . To avoid bleeding risk and in alternative to the activated form there is a rationale to use protein $\mathrm{C}$ zymogen in severe sepsis. In a double blind randomized study, 40 children with purpura fulminans and septic shock were randomized to receive placebo or non-activated protein $\mathrm{C}$ concentrate at various dosages, and in all treated patients conversion to activated form was observed, significantly correlated with drug dosage. ${ }^{26} \mathrm{~A}$ novel randomized prospective study on the outcome and changes in clotting and inflammatory parameters in children with severe sepsis receiving protein $\mathrm{C}$ concentrate is ongoing in Italy (Pediatric Intensive Care $\mathrm{C}$ protein HEmostasis PICCHE Study) and immune suppressed patients are also included.

\section{Inhibitors of inflammation}

TM by binding to thrombin converts protein $\mathrm{C}$ to APC and inhibits inflammatory process. In a randomized controlled study recombinant TM (rTM) significantly improved DIC, particularly in controlling bleeding. Further inhibitors of inflammation being investigated are antiselectin antibodies, which when associated with heparin may block leukocyte and platelet adhesion, and interleukin-10, which prevents coagulation activation induced by endotoxemia. 


\section{Conclusions}

Management of sepsis related coagulopathy should take into consideration combination treatments aimed at inhibition of TF activated coagulation in combination with restoration of anticoagulant pathways, as well as cytokine removal. In spite of promising results from initial studies, additional trials are needed to define their clinical effectiveness in children with severe sepsis.

\section{References}

1. Levi M. Current understanding of disseminated intravascular coagulation. $\mathrm{Br} \mathrm{J}$ Haematol 2004;124:567-76.

2. Zeverleder S, Hack CE, Willemin WA. Disseminated intravascular coagulation in sepsis. Chest 2005;128:2864-75.

3. Fourrier F, Chopin C, Goudemand J, et al. Septic shock, multiple organ failure, and disseminated intravascular coagulation. Compared patterns of antithrombin III, protein $\mathrm{C}$, and protein $\mathrm{S}$ deficiencies. Chest 1992;101:816-23.

4. Mann KG. Biochemistry and physiology of blood coagulation. Thromb Haemost 1999;82:165-74.

5. Levi M, de Jonge E, van der Poll T. Plasma and plasma components in the management of disseminated intravascular coagulation. Best Practice Res Clin Haematol 2006;19:127-42

6. Franco RF, de JE, Dekkers PE, et al. The in vivo kinetics of tissue factor messenger RNA expression during human endotoxemia: relationship with activation of coagulation. Blood 2000;96:554-9.

7. Neumann FJ, Marx N, Gawaz M, et al. Induction of cytokine expression in leukocytes by binding of thrombin-stimulated platelets. Circulation 1997;95:2387-94.
8. Aird WC. Vascular bed-specific hemostasis: role of endothelium in sepsis pathogenesis. Crit Care Med 2001;29:S28-S34.

9. Broze GJ Jr. Tissue factor pathway inhibitor and the revised theory of coagulation. Ann Rev Med 1995;46:103-12.

10. de Jonge E, Dekkers PE, Creasey AA, et al. Tissue factor pathway inhibitor (TFPI) dose-dependently inhibits coagulation activation without influencing the fibrinolytic and cytokine response during human endotoxemia. Blood 2000;95:11249.

11. Hermans PW, Hibberd ML, Booy R, et al. $4 \mathrm{G} / 5 \mathrm{G}$ promoter polymorphism in the plasminogen-activator inhibitor-1 gene and outcome of meningococcal disease. Meningococcal Research Group. Lancet 1999;354:556-60.

12. Coughlin SR. Thrombin signalling and protease-activated receptors. Nature 2000;407:258-64.

13. Rezaie AR. Regulation of the protein C anticoagulant and antinflammatory pathways. Curr Med Chem 2010;17:2059-69.

14. Abraham E, Reinhart K, Svoboda P, et al. Assessment of the safety of recombinant tissue factor pathway inhibitor in patients with severe sepsis: a multicenter, randomized, placebo-controlled, single-blind, dose escalation study. Crit Care Med 2001;29:2081-9.

15. Abraham E, Reinhart K, Opal S, et al. Efficacy and safety of tifacogin (recombinant tissue factor pathway inhibitor) in severe sepsis: a randomized controlled trial. JAMA 2003;290:238-47.

16. Warren BL, Eid A, Singer P, et al. Caring for the critically ill patient High-dose antithrombin III in severe sepsis: a randomized controlled trial. JAMA 2001;286:1869-78.

17. Wiedermann CJ, Kaneider NC. A systematic review of antithrombin concentrate use in patients with disseminated intravascular coagulation of severe sepsis. Blood
Coagul Fibrinol 2006;17:521-6.

18. Gross SJ, Filston HC, Anderson JC. Controlled study of treatment for disseminated intravascular coagulation in the neonate. J Pediatr 1982;100:445-8.

19. Bernard GR, Vincent JL, Laterre PF, et al. for the recombinant human activated protein $\mathrm{C}$ worldwide evaluation in severe sepsis (PROWESS) study group. Efficacy and safety of recombinant human activated protein C for severe sepsis. N Engl J Med 2001;344:699-709.

20. Bernard GR, Ely EW, Wright TJ, et al. Safety and dose relationship of recombinant human activated protein $\mathrm{C}$ for coagulopathy in severe sepsis. Crit Care Med 2001;29:2051-9.

21. Dhainaut JF, Yan SB, Joyce DE, et al. Treatment effects of drotrecogin alfa (activated) in patients with severe sepsis with or without overt disseminated intravascular coagulation. J Thromb Haemost 2004;21924-33.

22. Vincent JL, Angus DC, Artigas A, et al. Effects of drotrecogin alfa (activated) on organ dysfunction in the PROWESS trial. Crit Care Med 2003;31:834-40.

23. Levi M. Benefit of recombinant human activated protein $\mathrm{C}$ beyond 28-day mortality: there is more to life than death. Crit Care Med 2003;31:984-5.

24. Martí-Carvajal AJ, Solà I, Lathyris D, Cardona AF. Human recombinant activated protein C for severe sepsis. Cochrane Database of Systematic Reviews 2011, issue 4, art. CD004388.

25. Silva E, de Figueiredo LF, Colombari F. Prowess-shock trial: a protocol overview and perspectives. Shock 2010;34:48-53.

26. de Kleijn ED, de Groot R, Hack CE, et al. Activation of protein $\mathrm{C}$ following infusion of protein $\mathrm{C}$ concentrate in children with severe meningococcal sepsis and purpura fulminans: a randomized, double-blinded, placebo-controlled, dose-finding study. Crit Care Med 2003;31:1839-47. 